\title{
Percepção dos alunos do ensino médio sobre os biomas de Mata Atlântica e Caatinga
}

\section{Perception of high school students about the Atlantic Forest and Caatinga biomes}

\author{
${ }^{1}$ Bernadete Fernandes de Araújo bio.berna@hotmail.com \\ ${ }^{2}$ Hilda Helena Sovierzoski
}

\begin{abstract}
RESUMO
No estudo sobre o contexto ambiental dos biomas de Mata Atlântica e de Caatinga, a percepção se baseia na investigação do conhecimento que cada indivíduo construiu nas relações culturais. Partindo dessa assertiva, este estudo objetivou analisar a percepção de 50 estudantes da $3^{\text {a }}$ série do Ensino Médio de uma escola pública, Alagoas sobre os biomas de Mata Atlântica e de Caatinga, principais biomas de Palmeira dos Índios. A pesquisa foi de natureza qualitativa e quantitativa, um estudo de caso, utilizou-se um questionário semi-estruturado para a coleta de dados e a análise de conteúdo. Os dados analisados corroboraram que os estudantes apesar de apresentarem concepções naturalistas sobre o meio ambiente, com maior frequência, desconheciam o bioma e a presença de fragmentos de matas na região, dos que descreveram os tipos e as características da vegetação, pautaram de acordo com a utilidade socioeconômica. Logo, no Ensino Biológico com a temática se faz necessário inserir concepções globalizantes para que os estudantes se tornem participantes de discussões coletivas de forma crítica e interferente no ambiente.
\end{abstract}

Palavras-chave: Percepção, Mata Atlântica e Caatinga, Ensino.

\begin{abstract}
$n$ the study on the environmental context of the biomes of the Atlantic Forest and Caatinga, the perception is based on the research of knowledge that each individual built on cultural relations. Based on this assertion, this study aimed to analyze the perception of 50 students of the 3rd high school grade of a public school, Alagoas on the biomes of the Atlantic Forest and Caatinga, major biomes of Palmeira dos Indios. The research was qualitative and quantitative nature, a case study, used a semi-structured questionnaire to collect data and content analysis. The analyzed data corroborated that students despite having naturalistic conceptions of the environment, more often unaware of the biome and the presence of parts of forests in the region, of which described the types and characteristics of vegetation, guided according to socioeconomic utility. So in Biological Teaching with the theme it is necessary to insert globalizing concepts for students to become participants in group discussions critically and interfering in the environment.
\end{abstract}

Key Words: Perception, Atlantic Forest and Caatinga, Teaching.

1 Professora de Ciências Biológica da Educação Básica rede estadual e municipal de Alagoas, Especialista em Tecnologia da Educação e Gestão Ambiental, Mestranda no PPGCIM/UFAL.

2 Prof ${ }^{a}$. Doutora Setor de Comunidades Bentônicas Programa de Pós-Graduação em Ensino de Ciências e Matemática (PPGECIM), Coordenaçâo de Aperfeiçoamento de Pessoal de Nível Superior (CAPES), Coordenadora Adjunta dos Mestrados Profissionais - Área de Ensino. 


\section{INTRODUÇÃO}

O processo de educar é um processo de construção que requer o embricamento múltiplo do saber. Portanto as influências dos aspectos biológicos, geográficos, históricos, psicológicos e culturais se inter-relacionam, por isso que educar para compreender o contexto ambiental é uma tessitura bastante complexa (LEFF, 2003).

Segundo Krasilchik (2004) o ensino de Biologia nas escolas, na maioria das vezes, encontra-se dissociado da realidade do aluno, ou seja, descontextualizado. Muitos conteúdos passaram a ser ofertados de forma linear e informativa, sem, no entanto, constituir estratégia didática que favorecesse a internalização do conhecimento.

O bioma de Mata Atlântica foi considerado um dos 25 hotspots de biodiversidade no mundo, tendo perdido $70 \%$ de suas espécies. Esse ambiente ocupa menos de $2 \%$ da superfície terrestre, abrigando cerca de $60 \%$ de todas as espécies terrestres do planeta (SIQUEIRA; LEMES, 2006). O bioma de Caatinga é tipicamente brasileiro e enfrenta inúmeros impactos socioambientais, muito deles por ação antrópica, como processo de desertificação, desmatamento, queimadas (FREIRE; PACHECO, 2003). Consequentemente provoca alteração na paisagem natural sendo considerado por Prado (2008) como bioma induzido pela ação humana.

Assim, um estudo sobre as temáticas da área de Ecologia, no interior de Alagoas, deve contemplar os biomas brasileiros, incluindo Mata Atlântica e Caatinga. O estudo da percepção ambiental pode apontar variáveis importantes no processo de ensino, como mencionado por Reigota (1991)que em todo e qualquer estudo que se queira desenvolver com Educação Ambiental se faz necessário conhecer previamente a concepção que os envolvidos no processo possuem sobre o ambiente. Isto por que o estudo sobre a percepção ambiental permitiu compreender o contexto ambiental que os alunos construíram, servindo de base na escolha das estratégias didáticas para facilitar o processo ensino aprendizagem desses biomas.

\section{1 Percepção Ambiental}

A percepção ambiental perpassa pela compreensão das interferências que os aspectos políticos, sociais e econômicos imprimem na sociedade. As impressões culturais, geradas pelos aspectos mencionados acima, determinam as relações que os seres têm com o ambiente e como cada indivíduo o concebe (BIZZO; CHASSOT, 2013).

Para Tuan (2012) “a percepção é tanto a resposta dos sentidos aos estímulos externos como a atividade proposital”. Essas, por sua vez, possuem certos fenômenos registrados claramente. No entanto, outros fenômenos retrocedem para a sombra ou então foram bloqueados. A percepção construída tem conotação diferente e pode representar a sobrevivência biológica, ou propiciar a satisfação enraizada na cultura.

O estudo da percepção, das atitudes, dos valores do meio ambiente tornou-se extraordinariamente complexo, pois uma pessoa é um organismo biológico, um ser social e um indivíduo ontológico (VIGOTSKI, 2007). Esses valores refletem os níveis que os seres humanos registram frente à grande variedade de estímulos ambientais que captam de seus respectivos meios (LEFF, 2006).

A temática ambiental tem conotação modal, pois a partir do século XXI verificou-se a ênfase, trata de vender a ideia "ambientalmente correta" (PORTILHO, 2005). Vive-se atualmente no ciclo em que questões ambientais tornaram-se objetos de consumo. Porém sabe-se que nos bancos escolares se constrói a ideologia libertadora, capaz de emancipar o ser para atuar no seu ambiente (FREIRE, 2004).Essa libertação advém da apropriação do conhecimento de forma crítica, para compreender que nos ambientes inexistem caixinhas, onde cada conhecimento pode ser compartimentalizado (GUIMARÃES, 2004). O que existe apenas é um embricamento intenso entre os fenômenos químicos e físicos, agindo dentro dos seres biológicos, ou se inter-relacionando e direcionando a dinâmica do ambiente.

Dessa forma faz-se urgente o pensar sobre a racionalidade ambiental. Nesse sentido discutiram-se algumas das ideias de Leff (2003), que mencionou: 
O significado de uma racionalidade ambiental que integre os potenciais da natureza, os valores humanos e as identidades culturais em práticas produtivas sustentáveis incluem as inter-relações complexas de processos ideológicos e materiais diferenciados. Os fundamentos epistemológicos e ontológicos do saber ambiental adquirem assim sentido para conceber uma estratégia capaz de construir uma nova ordem social (LEFF, 2003, p. 34).

Dentro desse contexto "o conhecimento deve comportar tanto uma diversidade como uma multiplicidade" (PENA-VEIGA, 2003, p. 53). O pensamento embasado somente nas ideias, na percepção do indivíduo, retira o meio de construção de um fazer pedagógico multidimensional (GUIMARÃES, 2004).

Nos discursos ambientais, o fato de ignorar o contexto sócio histórico advém juntamente com as políticas conservadoras. A percepção necessária à construção de individuo crítico deixa de ser mobilizada, compreendendo-se que o indivíduo crítico deve ser aquele capaz de fazer inferências e de emitir julgamentos no meio em que está inserido (FOUREZ, 1995). Assim, apreender a complexidade do ambiente implica em ampliar os horizontes, construir, desconstruir e reconstruir saberes, vivências, atitudes culturais (LEFF, 2003).

A percepção de toda a exuberância dos biomas de Mata Atlântica e Caatinga contribuem para o desenvolvimento da criticidade dos alunos. Essa atitude capacitou os alunos a atuarem de forma comprometida com o seu espaço, pois só se cuida daquilo que se conhece (GUIMARÃES, 2004).

Corroborando com essas ideias, Vigotski (2009) discutiu que as interações culturais determinaram a apreensão do conhecimento, pois os indivíduos introjetam esse saber através de atividades intrapsicológicas, das estruturas psicológicas superiores. Com isso, os significados passam a ser construídos mediante as interações sociais que se expressam na linguagem, a qual organiza o pensamento e consolida a aprendizagem. Essas incursões se constituem em objeto de reflexão no contexto educacional.

Esse estudo objetivou analisar a percepção ambiental dos estudantes da $3^{\mathrm{a}}$ série do Ensino Médio, constituindo nas concepções alternativas dos estudantes sobre a Mata Atlântica e Caatinga, biomas típicos do interior de Alagoas, local onde foi realizada a pesquisa.

\section{METODOLOGIA}

Os estudantes que participaram dessa pesquisa estudavam em uma Escola Estadual na cidade de Palmeira dos Índios. A cidade situa-se em uma área de transição na mesorregião de Alagoas, em que os biomas se encontram e coexistem: o da Mata Atlântica e o da Catinga (IBGE, 2014).

Dentro desse contexto, o universo da pesquisa constituiu-se de 50 estudantes, de duas turmas do $3^{\mathrm{a}}$ sériedo Ensino Médio, a qual foi desenvolvida no segundo semestre de 2014. O critério de escolha da escola foi por esta ser uma escola que abrigava um contingente de alunos, oriundos tanto da zona rural quanto da zona urbana da cidade de Palmeira dos Î́ndios e de cidades vizinhas. Os diferentes locais de residências dos alunos, zona urbana ou rural, ampliaram a representatividade e a abrangência do estudo. A seleção da série deveu-se a essa ter no ensino de Biologia o conteúdo programático dos biomas brasileiros. O critério de escolha das turmas foi por sorteio, que aqui passaram a ser nominadas de turmas A e B.

A pesquisa foi delineada de acordo com os aspectos da pesquisa de campo qualitativa e quantitativo-descritiva e qualitativa. Como instrumento operacional de coleta dos dados utilizou-se o questionário, composto por uma série ordenada de perguntas, que foram respondidas por escrito e sem a interferência da pesquisadora. O referido instrumento foi semi-estruturado, com 10 questões, subdivididos em 2 seções, o perfil socioeconômico foi composto por 4 questões e 6 questões foram relativas a percepção ambiental dos alunos sobre a vegetação típicas dos biomas predominantes no município da referida pesquisa. 
Palmeira dos Índios em Alagoas é uma cidade interiorana, que se encontra na mesorregião desse estado, geologicamente, sobre o embasamento do maciço Pernambuco-Alagoas, com elevadas serras abauladas, evidenciando o intemperismo da região. A localização geográfica da cidade, região de transição entre a zona da mata e o sertão, permitiu que dois biomas, o da Mata Atlântica e da Caatinga, se encontrassem e coexistem em um mesmo local.

A vegetação predominante em Palmeira dos Índios se caracteriza como formação de matas, decídua, subxerófilas espinhosa, relacionada ao clima mais úmido. O bioma da Caatinga apresenta-se constituído de vegetação arbórea de pequeno e médio porte, bem como arbustos, vegetação rasteira, utilizadas para pastagem e nas atividades econômicas da agropecuária. Dentre os animais nativos podem ser encontrados cassacos (Didelphisalbiventris), furões (Galictisvittata), raposas (Vulpesvulpes), tatus (Euphractussexcinctus), guaxinins(Procyoncancrivorus), cotias (Fellis sp.) e peixes em abundância, além de aves, como galos de campina (Paroaria dominicana), papa-capim extravagante (SporophilaCaerules), periquito do mato(Cyanoliseuspatagonus), canário (Serenuscanariusdomesticus), nambu (ButiaIeiospayha), codorniz (Coturnixdactylisonans), rolinhas ( Passerdomesticus) e corujas (Athenecunicularia) (IBGE, 2014).

Os resultados dos questionários foram analisados de acordo com a proposta de Bardin (2011), sendo em seguida tabulados os dados, interpretados de acordo com a frequência semântica e agrupados em categorias. A partir das descrições, os dados foram organizados em duas seções, o perfil socioeconômico e a percepção ambiental dos alunos. A partir da seção de percepção ambiental, de acordo com as expressões dos alunos, verificou-se a necessidade de organizá-las em categorias. As inferências utilizadas, por sua vez, tinham por base os indicadores de frequência na análise semântica.

\section{RESULTADOS}

\section{1 Perfil socioeconômico}

Nas turmas A e B a faixa etária dos alunos analisados oscilou entre 15 a 20 anos de idade (Figura 1 A). Quanto ao gênero da turma A, no conjunto obteve-se $91,5 \%$ de meninas, enquanto na turma B apenas 38,5 \% eram do sexo feminino (Figura 1 B). Desses, 80\% residiam na zona rural e $20 \%$ na zona urbana para a turma A. No entanto, na turma B, 23\% residiam na zona rural e 77\% na zona urbana (Figura $1 \mathrm{C}$ ). A renda familiar dos alunos das turmas A e B variaram entre R\$150,00 até mais que R\$1.000,00 (Figura 1 D). 
Figura 1 - Perfil socioeconômico das turmas: faixa etária (A), gênero (B), localidade (C) e renda familiar (D).

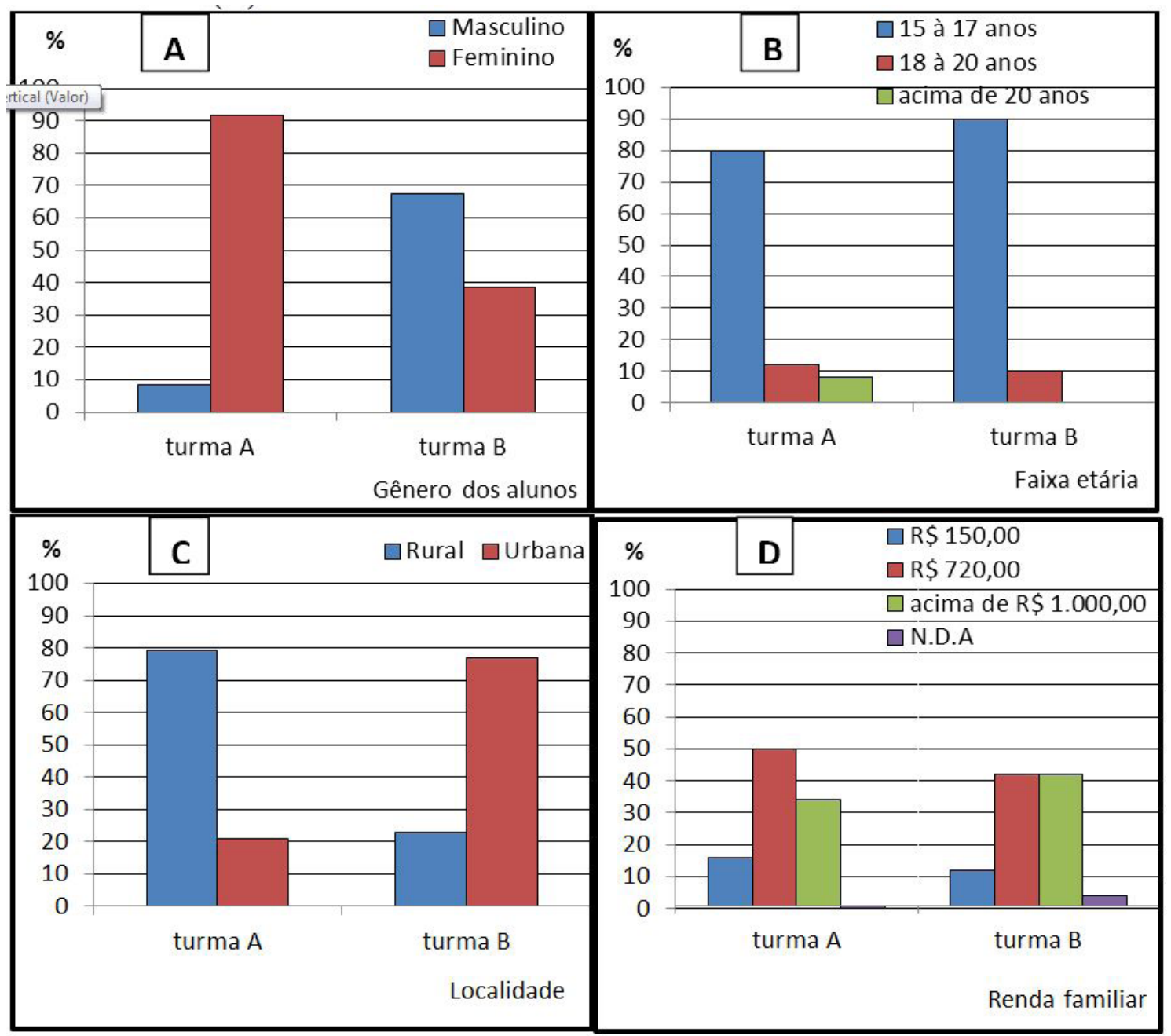

Fonte: Autoria própria

\section{2 Percepção ambiental}

Nesse aspecto analisado se fez necessário ordenar as informações em subcategorias. Quanto aos biomas presentes na cidade de Palmeira dos Índios e arredores, apenas 11,5\% dos alunos da turma A acertaram pontuando que os biomas de Palmeira dos Índios são de Mata Atlântica e Caatinga, os demais assinalaram respostas incorretas. Na turma B, todos os estudantes erraram, pois 83,5\% responderam Caatinga e Campos, 4\% Campos e Savanas, 4\% Mata de Várzea e Mangues e 8,5\% deixaram a questão em branco (Figura 2). 
Figura 2 - Percepção dos estudantes das turmas A e B com relação aos biomas.

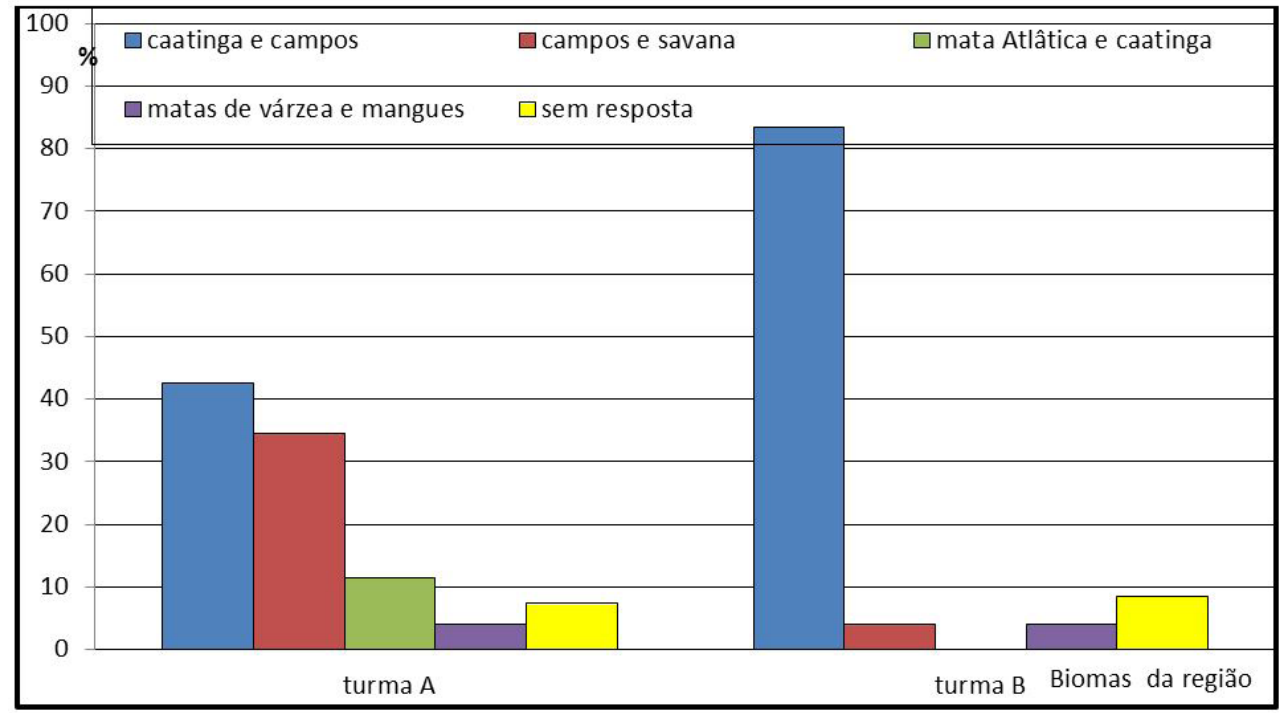

Fonte: Autoria própria

No questionamento do conceito de Meio Ambiente as categorias foram construídas utilizando critérios semânticos, a partir da frequência em que as palavras surgiram nas respostas dos alunos. Para a turma A, 19,5\% escreveram desmatamento e destruição, 11,5\% sobrevivência, 23\% localidade, 23\% beleza e paz, 7,5\% poluição. Os demais alunos deixaram de emitir resposta (Figura 2 B). Entre os participantes da pesquisa da turma B, 16,5\% percebiam como fonte de recursos, $50 \%$ poluição, $16,5 \%$ sentiam necessidade de preservar o meio ambiente e 17\% deixaram de responder (Figura 3).

Nas expressões os alunos fizeram referência de meio ambiente à local onde vivem os seres vivos, ou a fonte de recursos e interação entre os seres vivos, "Como um lugar benéfico para os seres vivos, que traz inúmeros benefícios e recursos" (aluna1 da turma A).Outros estudantes apresentaram concepção antropocêntrica, como a seguinte definição de meio ambiente: "lugar onde vivemos, onde estamos, o nosso meio de sobrevivência" (aluna 6 da turma A).

O desmatamento ou a destruição surgiu como subcategorias que representa a percepção do aluno para conceituar o meio ambiente, "Eu vejo o meio ambiente um pouco destruído pelo ser humano, desmata as florestas para plantar capim” (estudante 17 da turma A). Com isso evidenciou que o homem foi o causador da destruição do ambiente, pois desmatou para plantio de capim, esta ação está ligada a atividade econômica da cidade que é a agropecuária.

Outra colocação de um dos alunos ao tentar conceituar meio ambiente, chamou a atenção o apelo que um dos alunos fez para a preservação do meio ambiente "Precisando ser mais preservado, pois nenhuma tecnologia do século XXI substitui o meio ambiente” (aluno 29 da turma B). 
Figura 3 - Percepção dos estudantes das turmas A e B com relação ao conceito de ambiente.

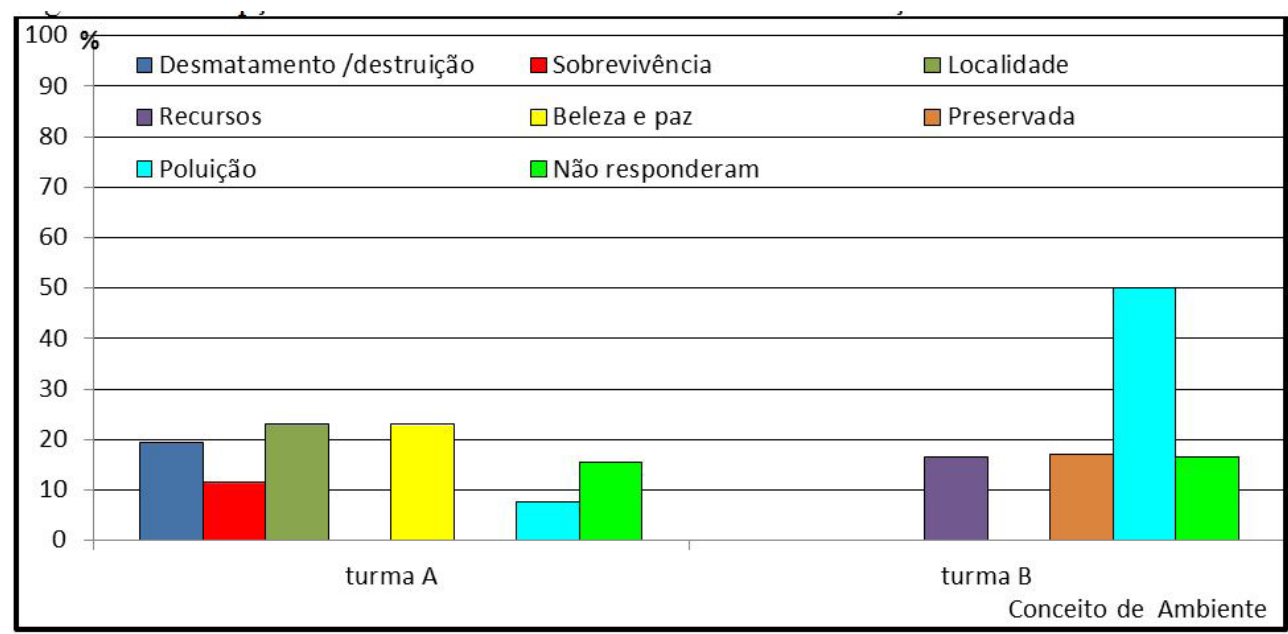

Fonte: Autoria própria

Para as características da vegetação dos biomas Mata Atlântica e Caatinga obteve-se diferentes subcategorias (Figura 4).

Figura 4 - Percepção dos estudantes das turmas A e B com relação às características da vegetação.

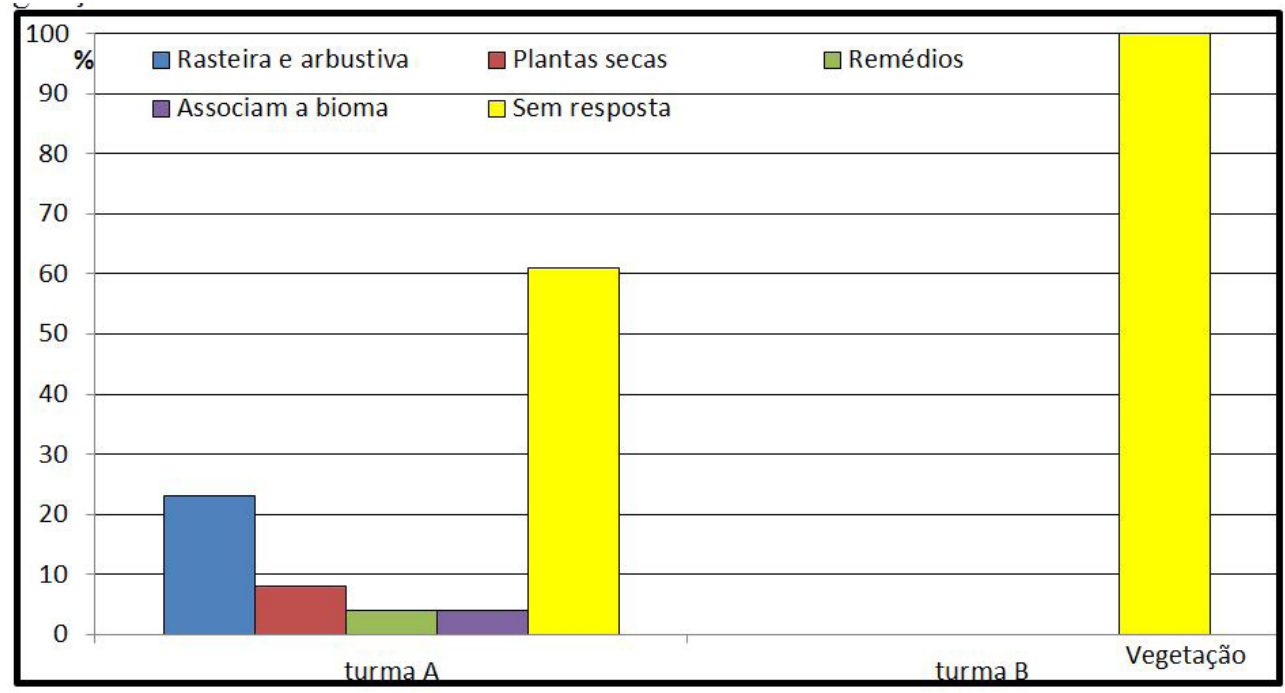

Fonte: Autoria própria

Na turma A: 23\% assinalaram plantas rasteiras, arbustivas e arbóreas, tendo como elementos significantes plantas baixas, campos, plantas altas ou pequenas. Na categoria plantas secas $8 \%$ das respostas indicou mata seca ou vegetação seca, 4\% escreveram plantas que serviam como remédios, 4\% pontuou como características da vegetação os biomas de Caatinga e Cerrado e 61\% dos alunos deixaram de expressar resposta. Na turma B todos os alunos deixaram a questão sem resposta (Figura 5). 
Figura 5 - Percepção dos estudantes das turmas A e B com relação aos tipos de plantas.

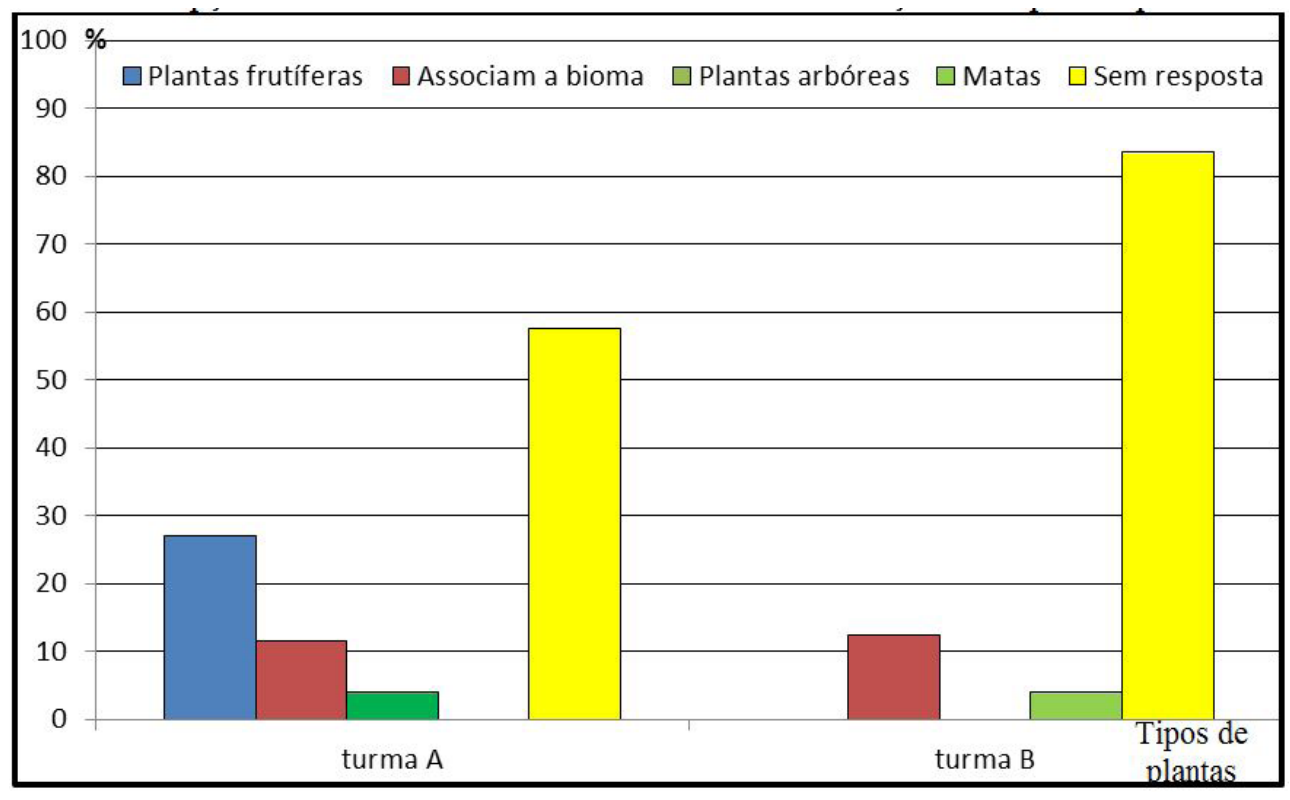

Fonte: Autoria própria

Quanto aos tipos de plantas encontrados em Palmeira dos Índios, Alagoas, 27\% dos alunos da turma A reconheceram e citaram as plantas frutíferas, $11,5 \%$ associaram a biomas, $4 \%$ citaram as plantas arbóreas e $57,5 \%$ deixaram de emitir resposta. No entanto na turma B obtiveram-se 3 categorias, $4 \%$ mencionado as matas, 12,5 associaram a biomas e $83,5 \%$ se recusaram a emitir resposta.

Percebeu-se que o estudante pontuou a presença de espinho, que é uma das características da Caatinga. Nesse tipo fitofisionômico predominam as espécies arbóreas e arbustivas da caatinga, árvores frutíferas como umbuzeiro (Spondias tuberosa), angico (Anadenanthera colubrina), cajueiro (Anacardium occidentale) e fragmentos de matas, com espécies de jurema (Mimosa tenuiflora), espinheiro (Senegalia polyphylla), marmeleiro (Ruprechtia laxiflora), catingueira (Caesalpinia pyramidalis) que estão sendo substituídas por pastagens (IBGE, 2014).

Além dessas plantas, se observaram representantes da Mata Atlântica, como a sucupira (Pterodonem arginatus), a umbaúba (Cecropia pachystachya), a sapucaia (Lecythis pisonis) e o oitizeiro (Licania tomentosa). Verificou-se que a categoria características da vegetação e o tipo foram correlatos, assim os resultados foram semelhantes. Os alunos da turma A ampliaram as respostas citando, além da percepção natural, a socioeconômica. Os alunos da turma B, pelas frequências das expressões nesse quesito, associaram com inconsistência conceitual.

No que se refere à existência de matas nos arredores do município em questão, 38\% dos alunos da turma $\mathrm{A}$ reconheceram, citando a Reserva Indígena Mata da Cafurna e da Catarina. Enquanto que o restante desconhecia as matas existentes na região de Palmeira dos Índios, Alagoas. Para a turma B, 25\% dos alunos reconheceram a presença das matas, os demais desconheciam (Figura 6).

A frequência de alunos que desconheciam os fragmentos de matas existentes correspondeu a 61,5\% para a turma A. Verificou-se que na turma B a frequência subiu para 75\%. Palmeira dos Índios encontra-se na zona urbana, em algumas áreas. Observou-se uma diversidade de vegetação típica de Mata Atlântica. A Reserva Indígena da Mata da Cafurna representa uma dessas áreas, localizada em local íngreme, sob a responsabilidade da FUNAI. Outras áreas concentradas em propriedades particulares, como na Mata da Catarina, também se verificam aglomerados representantes desses biomas. 
Figura 6 - Percepção dos estudantes das turmas A e B quanto à existência de matas.

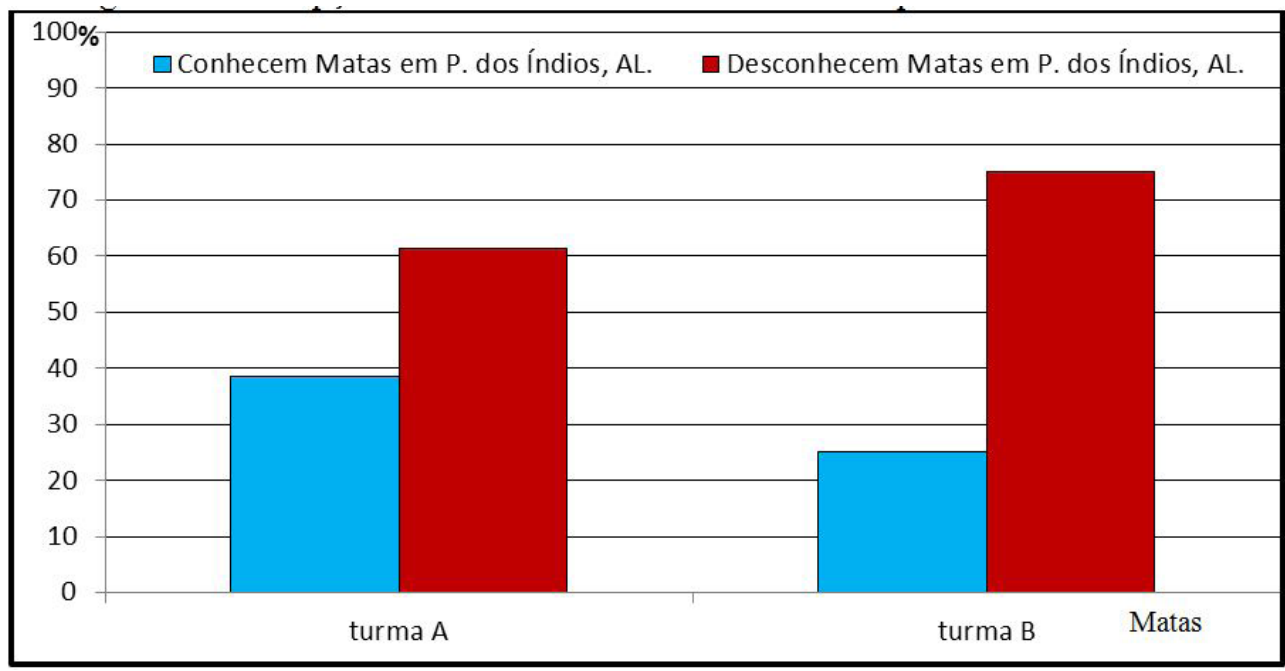

Fonte: Autoria própria

Os impactos observados em Palmeira dos Índios, para os alunos da turma A, 27\%indicaram o lixo como sendo um dos impactos ambientais vistos no percurso da casa deles à escola, 15,5\% citaram o desmatamento, $15,5 \%$ se referiram à seca, $4 \%$ poluição dos rios e $38 \%$ deixaram de responder. Os alunos da turma $\mathrm{B}$ perceberam a questão da seguinte forma: tendo 37,5\% respondido como fator principal o lixo, 12,5\% mencionaram o desmatamento, $4 \%$ comentaram sobre a falta de saneamento básico e $46 \%$ deixaram de emitir resposta.

Figura 7 - Percepção dos estudantes das turmas A e B sobre os impactos ambientais.

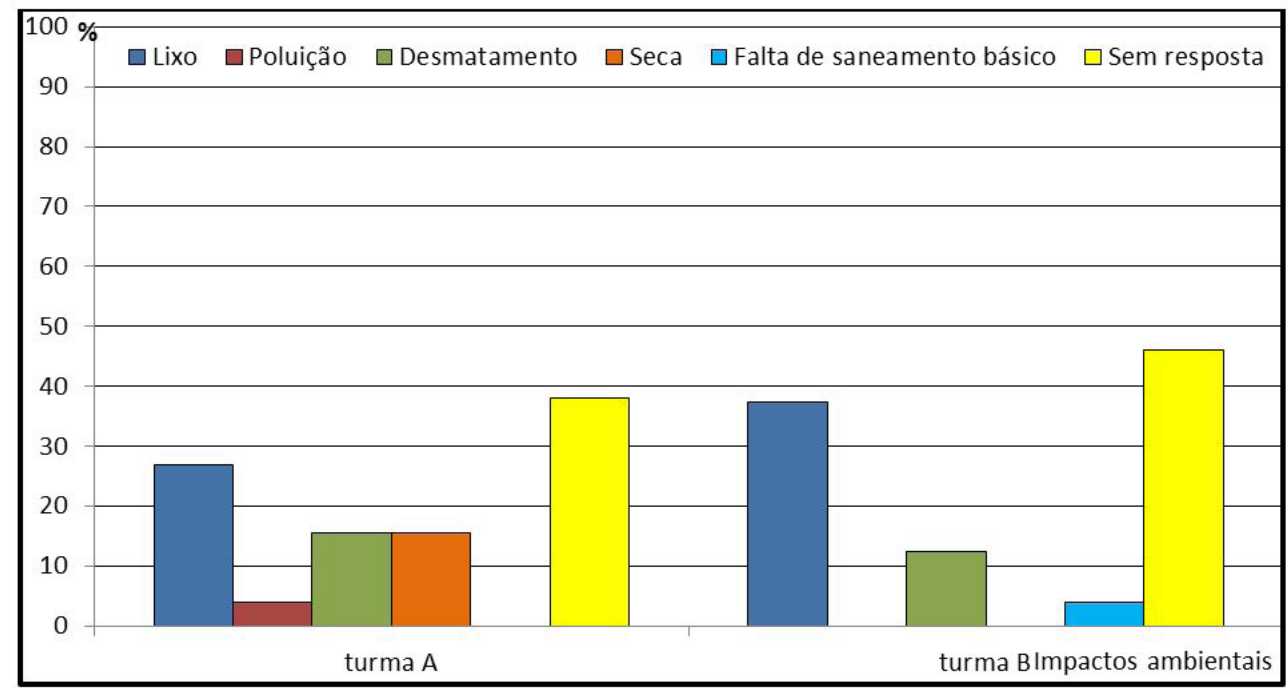

Fonte: Autoria própria.

\section{DISCUSSÃO}

O perfil socioeconômico demonstrou semelhança entre as duas turmas, a faixa etária, que oscilou entre17 a 21 anos de idade e também a distribuição de renda familiar ficou entre $\mathrm{R} \$ 150,00$ e acima de R\$1.000,00. Com base nas informações do IBGE (2014), esse público se encontra na classe social D à E (com2 a 4 salários mínimos por mês). Quanto ao gênero, na turma A prevaleceu o sexo feminino, enquanto na turma B observou-se uma 
turma heterogênea. Outro ponto evidenciado, com maior frequência entre os estudantes da turma A, foi residirem na zona rural, enquanto que os alunos da turma B principalmente na zona urbana.

A frequência de estudantes da turma A que acertou a questão quanto aos biomas predominantes em Palmeira dos Índios foi baixa, porém nenhum estudante da turma B respondeu corretamente a questão. Fato que diverge do que as Diretrizes Nacionais preconiza para a Educação Básica (1996), um ensino contextualizado.

Quanto ao conceito de meio ambiente observou-se que os alunos apresentaram uma visão contemplativa do ambiente, devido à presença dos recursos naturais, que foram considerados lindos e traziam paz. Segundo Sauvé et al. (2001), que trabalhou com as estratégias pedagógicas junto as questões ambientais, quando o ambiente passa ser percebido pelos alunos com concepções contemplativa, também deve inserir discussões que estimule os estudantes a adotar atitudes ambientalmente corretas.

Alguns alunos comentaram sobre os seres vivos que encontraram nos biomas estudados, apresentando visão antropocêntrica. Observou-se que os alunos da turma A apresentaram concepções naturalistas. Para Reigota (1991) essas concepções se baseiam na percepção dos elementos naturais do ambiente, sem dimensionar a interferência humana nas inter-relações entre os aspectos bióticos e abióticos.

Outra subcategoria quando questionados sobre o conceito de meio ambiente foi à percepção do desmatamento, a destruição pela ação humana. Para Diegues (1994) a concepção antropocêntrica centra o homem na natureza. Logo, os recursos naturais devem ser para ele usufruir. Nessa concepção prevalece à dicotomia entre o homem e a natureza, na qual a natureza é transformada para atender as necessidades do homem.

Nessa pesquisa evidenciou que os estudantes da zona urbana enfaticamente apontaram a poluição como conceito de meio ambiente, enquanto que os alunos da zona rural apresentaram uma visão contemplativa do ambiente como local que traz paz e como fonte de recursos. Esses dados corroboram as pesquisas de Tuan (2012), que demonstrou como as vivências influenciaram na construção das impressões. Logo, se faz necessário tecer mais discussões para desenvolver a visão globalizante em que os alunos discutiram o papel da Ciência das Tecnologias da Cultura, da Sociedade e do Meio Ambiente.

Nesta subcategoria percebeu a presença de estudantes que se expressaram de forma clara sobre a preservação da natureza, alertando que os avanços tecnocientíficos substituem o meio ambiente. Dias (2004), Brugger (2004), Freire (2008), Praia et al. (2007) recomendaram que os estudantes ampliem sua concepção de mundo visualizando os pontos positivos e negativos.

Ao analisar as razões que conduziram os alunos atribuírem meio ambiente a impactos ambientais, advém do enfoque que foi dado na difusão das premissas norteadoras da Educação Ambiental e ao Ensino de Ciências. Essas premissas surgiram mediante as reflexões sobre os desequilíbrios provocados pelas consequências do avanço tecnocientíficos (PRAIA et al., 2007). Entre os slogans do Ensino de Ciências e da Educação Ambiental foram às pesquisas e as denúncias da jornalista Raquel Carson, na década de 60, em seu livro intitulado primavera silenciosa com o qual evidenciou o uso abusivo dos agrotóxicos Dicloro - Difenil-Tricloroetano - DDT constituiu assim a segunda onda da educação ambiental, cujo foco foi os desastres ambientais (CARSON, 1980).

Quanto ao conceito de meio ambiente ao se trabalhar com a perspectiva dessas duas áreas de ensino, Sauvé (2005) advertiu sobre a importância de transpor a visão reducionista pautada no utilitarismo antropocêntrico. Recomenda ainda que os processos de ensino devam inserir reflexões sobre o meio ambiente para que os alunos o percebam como a trama da vida, onde se encontra a natureza, a identidade cultural, as relações com o outro e com o mundo.

Sendo assim, essas recomendações constituem de estratégias que possibilitam ao estudante a compreensão dos papeis do homem na natureza, pois a cultura se consolida na dialogicidade dos seres humanos, que refletem e reestruturam suas concepções de ambiente (VIGOTSKI, 2007). Essas reflexões envolvendo as conjecturas 
sociopolíticas e econômicas ampliam a visão dos impactos positivos e negativos, legitimando o ser humano a tomar decisões conscientes.

Algumas expressões da turma A foram selecionadas, pois os estudantes dessa turma obtiveram maior participação nas respostas, comparadas com a turma B. Os participantes da turma A centraram-se nas características da vegetação bem próxima as enunciadas pelo IBGE (2014). Analisando as expressões, se buscou observar qual a resposta para os tipos de biomas predominantes em Palmeira dos Índios, Alagoas. Uma estudante elencou Campos e Caatinga. Empiricamente, essa colocação faz alusão à paisagem natural de Palmeira dos Índios, que se encontra sofrendo rápida modificação por ação antrópica, pois a vegetação nativa cedeu espaço a agropecuária, confundindo-se com campos naturais.

Analisando os resultados, o desmatamento constituiu uma das categorias pontuadas pelos estudantes como responsável pela alteração da paisagem natural. No município um dos principais pólo de desenvolvimento de sua região é a expansão urbana e as atividades agropecuárias (IBGE, 2014). Moura (2006) alertou que o desmatamento acentuado pode ter sido o principal fator responsável pelo avanço da vegetação de caatinga sobre área de Mata Atlântica.

Quanto aos impactos observáveis em Palmeira dos Índios, Alagoas, os alunos mencionaram o lixo, em decorrência da crise ambiental. De acordo com Quintas (2004) a gênese dessa crise se estabeleceu na desequilibrada inter-relação entre o homem e dele com a natureza. Para Brugger (2004) a revolução científica surgiu no século XVIII, alavancando a crise ambiental atual. Com o desenvolvimento do conhecimento tecnocientíficos, intensificou-se perda da qualidade de vida. As consequências da revolução industrial foram desastrosas para a biodiversidade. Comparando os resultados da pesquisa de Souza et al. (2014) sobre a percepção ambiental da população urbana próxima ao rio Buriti no município de São Bernardo e Maranhão, com os resultados dessa pesquisa verificaram-se que o lixo foi pontuado como um dos impactos ambientais que comprometem a vida dos seres aquáticos,.

Uma das atividades socioeconômica de Palmeira dos Índios trata-se da agropecuária que acarretou na modificação da paisagem natural para ceder espaço para os ambientes agropecuários, satisfazendo as necessidades humanas. Com isso se reduziram a biodiversidade, além dos efeitos causados pela devastação e ouso de agrotóxicos utilizados para impedir a proliferação da vegetação nativa. Na investigação de Proença et al., (2014) sobre a percepção dos alunos, identificaram o desmatamento como uma das variáveis apresentadas que influência a diminuição ou a descaracterização dos biomas.

Para Lima (2008), a educação deve inserir a dialogicidade com a sociedade, visando investigar o modo de construção social dos problemas ambientais e de como a representação desses problemas condicionam fortemente a reação dos indivíduos.

Logo, ao trabalhar com a variável apresentada pelos alunos, quanto ao desmatamento, deve-se envolvê-los, usando uma estratégia que se efetiva mediante o desenvolvimento de pesquisas sobre a vegetação nativa da região, seguida de busca de parcerias para captar mudas nativas e interagir com a comunidade incentivando o cultivo das mesmas. Com isso consolidaria defendido por Sauvé (2005), superando a dicotomia entre o homem e natureza, estabelecida com a revolução industrial.

\section{CONSIDERAÇÕES FINAIS}

O estudo da percepção dos estudantes contribuiu para compreender que estes estudantes apresentaram impressões arraigadas em sua cultura. Os que residiam na zona rural apresentaram indicadores de acordo com as vivências e observações do seu entorno. Com isso reconheciam os fatores ligados atividade rural. Os de zona 
urbana apresentaram os indicadores que despertaramaatençãoligada aos aspectos de consumo. Com maior frequência as duas turmas desconheciam os biomas típicos da sua região.

O estudo apresentou variáveis que ancoram e reafirmam que a percepção ambiental é um processo, envolvendo construções históricas e sociais, vivenciadas em cada cultura. Nessa pesquisa a maioria dos alunos expressou desconhecer os biomas de Mata atlântica e Caatinga típicos da região.

Quanto ao conceito de meio ambiente observou-se que os estudantes apresentaram concepções naturalistas, descrevendo o meio ambiente como a localidade dos seres vivos e como fontes de recursos essenciais a sobrevivência, representando um ambiente bonito. Assim como também reconheceram a poluição e fizeram alusão ao conceito de meio ambiente, ao estado em que se encontra a natureza.

A descrição feita pelos estudantes das características e os tipos de plantas existentes no município, foram às categorias que obtiveram menor frequência nas respostas. Entre aqueles que se expressaram, relataram as características e os tipos de plantas conforme a utilidade socioeconômica. Os alunos da turma A também fizeram descrições próximas às utilizadas pelos teóricos considerados neste estudo, pois conceberam as plantas em consonância com as características e utilidades, tanto para atividades econômicas como para o consumo humano, citando as plantas medicinais e frutíferas.

Tendo como base o que foi analisado, para que o Ensino de Biologia sobre os biomas de Mata Atlântica e Caatinga cumpra com o seu objetivo, se faz necessário conhecer as percepções dos estudantes. Essas percepções se configuram nas variáveis que permitem um planejamento mais específico dentro de uma concepção holística e sistêmica do ambiente, envolvendo o contexto sócio histórico dos participantes. 


\section{REFERÊNCIAS}

BARDIN, L. Análise de Conteúdo. São Paulo: 7ªed., 2011.

BRÜGGER, P. Educação ou Adestramento Ambiental? 3ª ed. Chapecó: Argos; Florianópolis: Letras Contemporâneas, 2004.

CARSON, R. Primavera silenciosa. Barcelona: Grijalbo, 1980.Contemporâneas, 2004.

DIAS, G. F. Educação ambiental: princípios e práticas. São Paulo: 9ª ed., Gaia, 2004.

DIEGUES, A. C.O mito da Natureza encantada. São Paulo: Núcleo de Pesquisa em Áreas Úmidas do Brasil, 1994.

FAGGIONATO, S. Percepção ambiental. Disponível em:< $<$ www.educar.sc.usp.br/textos $>$. Acesso em: 12 set. 2014.

FOUREZ, G.A construção das ciências: introdução à filosofia e à ética das ciências. São Paulo: Editora da Universidade Estadual Paulista, 1995.

FREIRE, N.C.; PACHECO, A.P. Desertificação na região de Xingó: análise e mapeamento espectro-temporal. In: III Colóquio Brasileiro de Ciências Geodésicas, Curitiba. Anais. Curitiba, 2003.

FREIRE, P. Medo e ousadia. São Paulo: Ed. Paz e Terra, 2008.

FREIRE, P. Pedagogia da autonomia: saberes necessários à prática educativa. São Paulo: $30^{\mathrm{a}}$ ed.. Paz e Terra, 2004.

GARRIDO, L.S.; MEIRELLES, R.M.S. Percepção sobre o meio ambiente por alunos das séries iniciais do Ensino Fundamental: considerações à luz de Marx e de Paulo Freire. Ciênc. Educ. Bauru, v. 20, n. 3, p.671-685, 2014.

GUIMARÃES, M. Educação ambiental crítica. In. LAYRARGUES, P. P. (coord.). Identidades da educação ambiental brasileira. Brasília: Ministério do Meio Ambiente, 2004.

IBGE, Instituto Brasileiro de Geografia e Estatística, infográficos: dados gerais do município de Palmeira dos Índios, Alagoas. Disponível em:<http://cidades.ibge.gov.br> . Acesso: 21 ago. 2014.

KRASILCHIK, M. Prática de Ensino de Biologia. São Paulo: 4ª ed., EDUSP, 2004.

KRASILCHIK, M. Reformas e realidade: o caso do ensino das ciências.São Paulo em Perspectiva.v. 14, n.1, p.85-93, 2000.

LEFF, E. A complexidade Ambiental. São Paulo: Cortez, 2003.

LEFF, E. Racionalidade Ambiental: A apropriação social da natureza. Rio de Janeiro: Universalização brasileira, 2006.

LIMA, G. F. da C. Educação ambiental crítica: do socioambientalismo às sociedades sustentáveis. Educação e Pesquisa. São Paulo, v. 35, n. 1, p. 145-163, jan./abr. 2008.

MMA - MINISTÉRIO DO MEIO AMBIENTE. 2007. Áreas Prioritárias para a Conservação, Uso Sustentável e Repartição de Benefícios da Biodiversidade Brasileira: Atualização - Portaria MMA n. 09, de 23 de janeiro de 2007. Série Biodiversidade, 31. 2007. 
MMA. Ministério do Meio Ambiente. Caatinga. Brasília, 2014. Disponível em: <http://www.mma.gov.br/ biomas/caatinga $>$. Acesso: 03 jan. 2014.

MMA. Ministério do Meio Ambiente. Mata Atlântica: manual da adequação ambiental. Brasília: MMA/ SBF, 2010.

MOURA, F. de B. P. A Mata Atlântica em Alagoas. Maceió: EDUFAL, 2006.

PENA-VEGA, A.O despertar ecológico: Edgar Morin e a ecologia complexa. Rio de Janeiro: Garamond, 2003.

PORTILHO, F. Sustentabilidade ambiental, consumo e cidadania. São Paulo, Cortez, 2005.

PRADO, D. E. As Caatingas da América do Sul. In: LEAL, R. I.; TABARELLI, M.; SILVA, J. M. C. da. Ecologia e conservação da Caatinga. Recife: Ed. Universitária da UFPE, 2003.

PRAIA, J.; GIL-PÉREZ, D.; VILCHES, A. O papel da natureza da ciência na educação para a cidadania. Ciência \& Educação, v. 13, n. 2, p. 141-156, 2007.

PROENÇA, M. de S.; OSLAJZ, E. U.; DAL-FARRA, R. A. As percepções de estudantes do Ensino Fundamental em relação às espécies exóticas e o efeito antrópico sobre o ambiente: uma análise com base nos pressupostos da CTSA - Ciência - Tecnologia - Sociedade - Ambiente. Pesquisa em Educação Ambiental, v. 9, n. 2, p.51-66, 2014.

QUINTAS, J. S. Educação no processo de gestão ambiental: uma proposta de educação ambiental transformadora e emancipatória. In: LAYRARGUES, P. P. (Org.). Identidades da educação ambiental brasileira. Brasília: Ministério do Meio Ambiente, 2004.

REIGOTA, M. O meio ambiente e suas representações no ensino de ciências. Boletim da Comissão Interinstitucional sobre Meio Ambiente e Educação Universitária. São Paulo, 1991.

RICKEFS, R. E. A economia da natureza. Rio de Janeiro: Guanabara Koogan, 2012.

SAUVÉ, L. L'éducationrelative à l'environnement: une dimensionessentielle de l'éducationfondamentale. In Gohier, Christiane E. Laurin, Suzanne (2001). La formationfondamentale - Un espace à redéfinir. Montréal: LesÉditions Logiques, p. 293-318.

SAUVÉ, L. Educação Ambiental: possibilidades e limitações. Educação e Pesquisa. São Paulo, v.31, n. 2, p. 317-322, maio/ago, 2005.

SIQUEIRA, J. A.; LEME, E. M.C. Fragmento de Mata Atlântica do Nordeste: Biodiversidade, Conservação e suas Bromélias. Rio de Janeiro: Jacksson Estúdio, 2006.

SOUSA, E. O. F. de.; BRITO, N. M.; JUNIOR, O. P. A. Percepção Ambiental da população urbana próxima ao rio buriti no município de São Bernardo/MA. Pesquisa em educação Ambiental. v.9, n. 2, p.37-50, 2014.

TOZONI-REIS, M. F. C. Educação ambiental: natureza, razão e história. Campinas: 2 ed. rev., Autores Associados, 2008.

TUAN, Y. -F.Topofília: Um estudo da percepção, atitudes e valores do meio ambiente. Londrina: Eduel, 2012.

VIGOTSKI, L. S. A formação social da mente: o desenvolvimento dos processos psicológicos superiores. São Paulo: 7 ed., Martins Fontes, 2007.

VIGOTSKI, L. S.A construção do pensamento e da linguagem. 2 ed., São Paulo: Editora WMF Martins Fontes, 2009. 